\title{
Height loss but not body composition is related to low back pain in community- dwelling elderlies: Shimane CoHRE study
}

\author{
Takeshi Endo ${ }^{1,2}$, Takafumi Abe ${ }^{2}$, Kenju Akai ${ }^{2}$, Tsunetaka Kijima ${ }^{2,3}$, Miwako Takeda², Masayuki Yamasaki ${ }^{2,4}$ \\ Minoru Isomura ${ }^{2,4}$, Toru Nabika ${ }^{2,5}$ and Shozo Yano ${ }^{2,6^{*}}$
}

\begin{abstract}
Background: Low back pain (LBP) is a common complaint in the elderly Japanese population. Although previous studies showed that height loss was associated with LBP, it remains unclear whether LBP is associated with body composition. The objective of the present study was to investigate whether body composition and physical characteristics, including height loss, were associated with LBP.
\end{abstract}

Methods: The present study is retrospectively registered, and the participants were 2212 community-dwelling Japanese people aged over 60 years who participated in the Shimane CoHRE study in 2016. We investigated the presence of LBP, body composition parameters (muscle, fat, body weight, and bone mass), physical characteristics (body height and height loss), chronic diseases, history of fall, smoking, and drinking habits. We examined the relationships of body composition parameters and physical characteristics with point prevalence of LBP using multivariate logistic regression.

Results: The point prevalence of LBP was $43.2 \%$ in women and 39.5\% in men. Logistic regression models showed that body height and body composition were not significantly associated with LBP; however, height loss was associated significantly with LBP in women and men (OR: 1.14, 95\% Cl: 1.08-1.20 and OR: 1.13, 95\% Cl: 1.06-1.21, respectively). Hypertension (OR: 1.32, $95 \%$ Cl: 1.04-1.69) and chronic heart disease (OR: 1.57, 95\% Cl: 1.01-2.43) in women and history of fall (OR: 1.70, 95\% Cl: 1.13-2.56) and cerebrovascular disease (OR: 1.88, 95\% Cl: 1.05-3.34) in men were significantly associated with LBP. However, body composition was not associated with LBP in either gender.

Conclusions: The present study demonstrated that height loss, but not body composition, was related to LBP in community-dwelling elderly people. To elucidate the cause of LBP, it is important to consider the relationship with height loss.

Keywords: Lumbago, Health examination, Geriatrics, Muscle mass

\section{Background}

Low back pain (LBP), a common symptom of the elderly, is associated with a marked decrease in health-related quality of life $[1,2]$ and physical function later in life [35]. Furthermore, LBP cause economic burdens on individuals, communities and governments, including direct costs for health-care and indirect costs of lost production and lost household productivity [6-9].

\footnotetext{
* Correspondence: syano@med.shimane-u.ac.jp

${ }^{2}$ Center for Community-Based Healthcare Research and Education (CoHRE),

Shimane University, Matsue-city, Shimane, Japan

${ }^{6}$ Department of Laboratory Medicine, Shimane University Faculty of

Medicine, Izumo-city, Shimane, Japan

Full list of author information is available at the end of the article
}

A previous survey reported that the point prevalence of LBP ranged from 12 to 33\%, 1-year prevalence ranged from 22 to $65 \%$, and lifetime prevalence ranged from 11 to $84 \%$ [10]. In the Japanese population, the point prevalence of LBP was reported to be $37.7 \%$ [11], suggesting that Japanese people have considerably higher rates of LBP than do individuals in other parts of the world. Therefore, prevention of LBP is an important issue for Japanese public health.

Many researchers have studied the physical characteristics of subjects with LBP. For example, LBP has been reported to be associated with overweight/obesity [1218] and substantial body height [19-22]. On the other

(c) The Author(s). 2019 Open Access This article is distributed under the terms of the Creative Commons Attribution 4.0 International License (http://creativecommons.org/licenses/by/4.0/), which permits unrestricted use, distribution, and reproduction in any medium, provided you give appropriate credit to the original author(s) and the source, provide a link to the Creative Commons license, and indicate if changes were made. The Creative Commons Public Domain Dedication waiver (http://creativecommons.org/publicdomain/zero/1.0/) applies to the data made available in this article, unless otherwise stated. 
hand, height loss has been reported to be associated with LBP [23, 24]. Furthermore, some have reported a relationship of LBP with high fat mass [25-27], while others have shown a relationship between LBP and muscle atrophy [28-30]. However, to the best of our knowledge, there have been no reports examining the relationship of LBP with body composition and height loss.

Therefore, the aims and objectives of the present study were to examine the relationship between body composition, physical characteristics, and LBP with respect to height loss in general community-dwelling older people.

\section{Methods}

\section{Study design}

This cross-sectional study is a part of the cohort study conducted by the Center for Community-based Healthcare Research and Education in Shimane University (Shimane CoHRE study). It is an ongoing health examination for the community-dwelling people in Unnan-city, Okinoshimacho and Ohnan-cho, Shimane Prefecture, Japan. The study protocol was approved by the Ethics Committee of Shimane University School of Medicine (\#3149) and Unnan City Hospital (\#20180004). Written informed consent was obtained from all participants.

\section{Study participants}

In this study, we used the CoHRE study data, which was collected from June to November 2016. A total of 3036 community-dwelling Japanese people participated in the health examinations. The inclusion criteria for this study were as follows: (1) individuals who were over 60 years old; (2) individuals answered the questionnaire regarding LBP and history of fall; (3) individuals whose demographic data, including age, gender, and the tallest recalled height were recorded; (4) individuals whose body compositions were examined; and (5) individuals who were informed of the protocol and purpose of the current study and consented to participate. According to the criteria, a total of 2212 subjects were included in the current study (Fig. 1).

\section{Low back pain}

The presence of LBP was assessed using self-reported questionnaire and face-to-face information. Participants were asked the following question: 'Do you have any low back pain at present: yes or no?' Those who answered 'yes' were defined as having LBP. This method was used in a previous study [31].

\section{Body composition parameters}

\section{Muscle, fat, body weight and bone mass}

Body composition and body weight were measured by bioelectrical impedance analysis (BIA) method with MC-780A multi-frequency segmental body composition analyzer (Tanita Co., Tokyo, Japan) [32, 33]. Body fat mass (kg), body fat ratio (\%), muscle mass of the arms and the legs $(\mathrm{kg})$, and body mass index (BMI) were automatically calculated.

Bone mass was measured using quantitative ultrasound (QUS) (Benus $\alpha$; Ishikawa Seisakusho, Ltd., Ishikawa, Japan). QUS has advantages including absence of exposure to radiation, low cost, and portability. The estimated values were compared to young adult mean (\%YAM) of the same gender. A value $100 \%$ means same value as healthy young men or women [34]. This measurement was performed in all areas except Okinoshima-cho.

\section{Physical characteristics \\ Body height and height loss}

The present body height was measured using a stadiometer. The tallest body height was obtained from self-reported questionnaire as follows: "What was your tallest height (when you were 20 years old)?" Height loss was calculated by the subtraction of the present height from the tallest height $[24,35]$.

\section{Covariates}

Other variables were obtained from the self-administered questionnaires. We inquired about age, gender, history of fall within 1 year (yes, no), smoking (yes, no), alcohol consumption (yes, no) and chronic disease (hypertension, dyslipidemia, diabetes, cerebrovascular disease, chronic heart disease: yes, no). These potential confounders were reported to be associated with musculoskeletal pain, including LBP [36-42].

\section{Statistical analysis}

The characteristics of study participants were compared between participants with LBP and those without using independent $t$-tests for continuous variables and $\chi^{2}$ tests for categorical variables. Although some data were not normally distributed, this analysis method was used because the number of participants was sufficiently large.

Multivariate logistic regression models stratified by gender were used to explore the association between the presence of LBP (dependent variable), body composition parameters, physical characteristics, and covariates (independent variables). According to these models, adjusted odds ratios (ORs) and 95\% confidence intervals of the LBP-related parameters were calculated. ORs were adjusted for age, body composition, and additional covariates such as body characteristics and the presence of chronic disease. We used for the following potential confounders: age, body height, muscle mass, fat mass, smoking, alcohol drinking, history of fall, hypertension, dyslipidemia, diabetes, cerebrovascular disease, chronic heart disease, and height loss. Body weight and BMI were not included as dependent variables of multivariate analysis because of their high Pearson's correlation coefficients with muscle mass and fat mass 


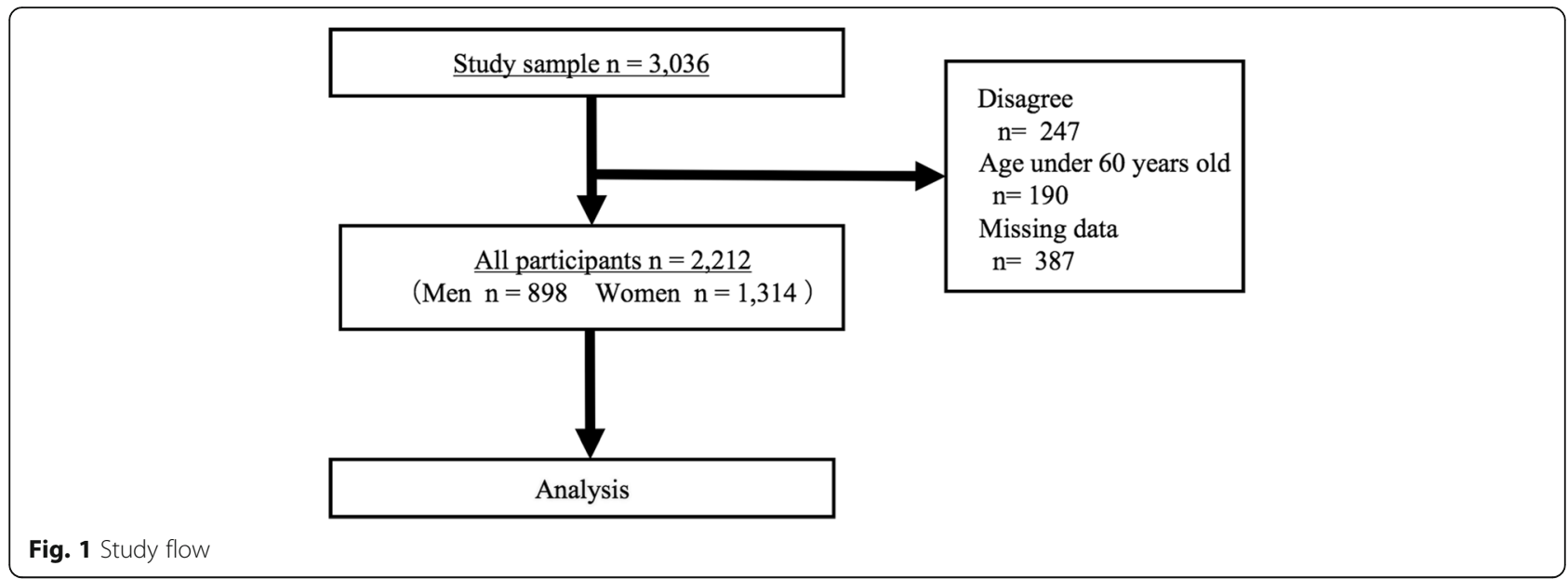

(Additional file 1: Table S1). We performed a multiple linear regression analysis to identify anthropometric parameters that were related to height loss, expressed as standardized $\beta$ and $95 \%$ confidence interval (CI).

The level of significance was set at $p<0.05$. All data were presented as the mean \pm standard deviation (SD). All statistical analyses were performed using the IBM
SPSS Statistics 22 software package (IBM Japan, Tokyo, Japan).

\section{Results}

Clinical characteristics of the study population

The characteristics of 2212 participants are shown in Table 1. The number of participants with LBP was 567

Table 1 Baseline characteristics of study participants according to low back pain

\begin{tabular}{|c|c|c|c|c|c|c|c|c|c|c|}
\hline & \multicolumn{5}{|c|}{ Women } & \multicolumn{5}{|l|}{ Men } \\
\hline & \multirow{2}{*}{\multicolumn{2}{|c|}{$\begin{array}{l}\text { No LBP } \\
n=747\end{array}$}} & \multirow{2}{*}{\multicolumn{2}{|c|}{$\frac{\mathrm{LBP}}{n=567}$}} & \multirow{3}{*}{$\begin{array}{l}p- \\
\text { value }\end{array}$} & \multirow{2}{*}{\multicolumn{2}{|c|}{$\begin{array}{l}\text { No LBP } \\
n=543\end{array}$}} & \multirow{2}{*}{\multicolumn{2}{|c|}{$\frac{\mathrm{LBP}}{n=355}$}} & \multirow[t]{3}{*}{$p$-value } \\
\hline & & & & & & & & & & \\
\hline & Mean & SD & Mean & SD & & Mean & SD & Mean & SD & \\
\hline Age(years) & 72.5 & 6.6 & 73.5 & 6.5 & 0.01 & 72.9 & 6.6 & 72.8 & 6.4 & 0.92 \\
\hline Body weight(kg) & 50.8 & 8.4 & 50.5 & 8.3 & 0.52 & 60.5 & 8.6 & 61.0 & 8.9 & 0.40 \\
\hline Body height (cm) & 150.6 & 5.9 & 149.1 & 5.7 & $<0.01$ & 163.1 & 6.1 & 162.7 & 6.2 & 0.42 \\
\hline Body mass index $\left(\mathrm{kg} / \mathrm{m}^{2}\right)$ & 22.4 & 3.4 & 22.7 & 3.4 & 0.11 & 22.7 & 2.8 & 23.0 & 2.8 & 0.16 \\
\hline Muscle mass(kg) & 14.2 & 2.0 & 14.0 & 2.1 & 0.21 & 20.2 & 2.9 & 20.4 & 3.2 & 0.25 \\
\hline Fat mass(kg) & 15.2 & 6.4 & 15.4 & 6.2 & 0.55 & 11.7 & 5.0 & 11.9 & 5.1 & 0.51 \\
\hline Bone mass \%YAM(\%) ${ }^{a}$ & 83.9 & 10.0 & 83.4 & 9.9 & 0.40 & 91.3 & 11.0 & 91.3 & 12.3 & 0.93 \\
\hline \multirow[t]{2}{*}{ Height loss (cm) } & 2.9 & 2.4 & 4.0 & 3.3 & $<0.01$ & 2.3 & 2.0 & 2.9 & 2.6 & $<0.01$ \\
\hline & $n$ & $\%$ & $n$ & $\%$ & & $n$ & $\%$ & $\mathrm{n}$ & $\%$ & \\
\hline Alcohol intake & 213 & 28.5 & 144 & 25.4 & 0.21 & 385 & 70.9 & 248 & 69.9 & 0.74 \\
\hline Current smoking & 8 & 1.1 & 5 & 0.9 & 0.73 & 79 & 14.5 & 62 & 17.5 & 0.24 \\
\hline History of fall & 113 & 15.1 & 96 & 16.9 & 0.38 & 56 & 10.3 & 58 & 16.3 & $<0.01$ \\
\hline Hypertension & 279 & 37.3 & 259 & 45.7 & $<0.01$ & 212 & 39.0 & 156 & 43.9 & 0.14 \\
\hline Diabetes mellitus & 68 & 9.1 & 45 & 7.9 & 0.46 & 77 & 14.2 & 49 & 13.8 & 0.87 \\
\hline Dyslipidemia & 240 & 32.1 & 195 & 34.4 & 0.39 & 97 & 17.9 & 67 & 18.9 & 0.70 \\
\hline Cerebrovascular disease & 11 & 1.5 & 15 & 2.6 & 0.13 & 24 & 4.4 & 28 & 7.9 & 0.03 \\
\hline Chronic Heart disease & 42 & 5.6 & 55 & 9.7 & $<0.01$ & 62 & 11.6 & 34 & 10.7 & 0.38 \\
\hline Community 1 & 317 & 42.4 & 218 & 38.4 & & 243 & 44.8 & 186 & 52.4 & \\
\hline Community 2 & 255 & 34.1 & 210 & 37.0 & & 152 & 28.0 & 87 & 24.5 & \\
\hline Community 3 & 175 & 23.4 & 139 & 24.5 & 0.34 & 148 & 27.3 & 82 & 23.1 & 0.08 \\
\hline
\end{tabular}

${ }^{a} n=1505 ;$ Community $1=$ Unnan city; $2=$ Oki-island; $3=$ Ohnan Cho 
(43.2\%) women and 355 (39.5\%) men. There was no significant difference in the prevalence of LBP between women and men. Women with LBP were significantly younger and shorter and showed greater height loss and higher prevalence of hypertension and heart disease compared to those without LBP. Men with LBP showed greater height loss and higher rates of history of falls compared to those without LBP. Conversely, body composition and bone mass were not significantly different with or without LBP in men and women. Furthermore, no significant difference was found in the prevalence of LBP among the three communities in both genders.

\section{Association between low back pain and covariates}

Next, we conducted multivariate logistic regression models for the presence of LBP in women and men. In women, body height (OR: 0.96, 95\% CI: 0.93-0.98, $p<$ 0.01 ) was negatively associated with the presence of LBP in Model 1 (Table 2). In model 2, however, height loss (OR: 1.14, 95\% CI: $1.08-1.20, p<0.01$ ) but not body height was significantly associated with LBP. Furthermore, the presence of hypertension (OR: 1.32, 95\% CI: $1.04-$ 1.69, $p=0.02$ ) and chronic heart disease (OR: 1.57, 95\% CI: $1.01-2.43, p=0.04$ ) had a significant association with LBP in women. In men, height loss (OR: 1.13, 95\% CI: $1.06-1.21, p<0.01$ ), history of fall (OR: 1.70, 95\% CI: $1.13-2.56, p=0.01$ ) and cerebrovascular diseases (OR: 1.88 , 95\% CI: $1.05-3.34, p=0.03$ ) were significantly associated with LBP (Table 3).

On the other hand, it was notable that no significant association was observed between LBP and body composition, including muscle mass and fat mass in both women and men. Furthermore, in a multiple linear regression analysis, height loss was associated inversely with height but was positively associated with weight in women (Additional file 2: Table S2).

\section{Discussion}

The objective of the present study was to investigate whether body composition and physical characteristics were associated with the presence of LBP. We found that LBP was significantly associated with height loss, independent of body height, body composition, lifestyle, history of fall or chronic diseases. These findings suggest that height loss may be a good predictor of the presence of LBP in the elderly, at least in the Japanese population. Furthermore, height loss-related skeletal degeneration/disorders presumably account for many mechanisms of LBP.

In the present study, body height was negatively associated with the presence of LBP in women. However, this is inconsistent with findings of previous studies that suggested a positive association between body height and LBP [19-22]. Body height was an independently positive risk factor for herniated lumbar disc [43]. Therefore, we adjusted by height loss to show that height loss, but not present body height, was significantly and independently associated with LBP in both genders. With aging, height loss progresses [44], related to vertebral fractures, reduced disk hydration, change of vertebral deformities, and decrease in lumbar disc height [45-50]. Chronic pressure on the spine, such as from obesity or occupational physical loading, is thought to be one of the causes of height loss $[46,51]$. Urquhart et al. demonstrated an association between obesity and reduced lumbar disc height [52]. Our study also showed a positive association between body weight and height loss in women, even if body height was considered.

Table 2 Odds ratios for low back pain in women $(n=1314)$ by multivariate logistic regression models

\begin{tabular}{|c|c|c|c|c|c|c|c|c|c|c|}
\hline \multirow[b]{3}{*}{ Age } & \multicolumn{5}{|c|}{ Model 1} & \multicolumn{5}{|c|}{ Model 2} \\
\hline & \multirow{2}{*}{$\frac{\mathrm{OR}}{1.00}$} & \multicolumn{3}{|c|}{$95 \% \mathrm{Cl}$} & \multirow{2}{*}{$\frac{\text { p-value }}{0.77}$} & \multirow{2}{*}{$\frac{O \mathrm{OR}}{0.99}$} & \multicolumn{3}{|c|}{$95 \% \mathrm{Cl}$} & \multirow{2}{*}{$\begin{array}{l}\text { p-value } \\
0.19\end{array}$} \\
\hline & & 0.98 & - & 1.02 & & & 0.97 & - & 1.01 & \\
\hline Body height & 0.96 & 0.93 & - & 0.98 & $<0.01$ & 0.98 & 0.95 & - & 1.00 & 0.08 \\
\hline Muscle mass & 1.02 & 0.95 & - & 1.11 & 0.55 & 1.01 & 0.93 & - & 1.10 & 0.74 \\
\hline Fat mass & 1.00 & 0.98 & - & 1.02 & 0.85 & 1.00 & 0.98 & - & 1.02 & 0.95 \\
\hline Smoking & 0.90 & 0.29 & - & 2.79 & 0.85 & 0.89 & 0.28 & - & 2.80 & 0.84 \\
\hline Alcohol & 0.90 & 0.70 & - & 1.16 & 0.43 & 0.91 & 0.70 & - & 1.18 & 0.47 \\
\hline History of fall & 1.05 & 0.77 & - & 1.42 & 0.77 & 1.05 & 0.77 & - & 1.43 & 0.76 \\
\hline Hypertension & 1.31 & 1.03 & - & 1.66 & 0.03 & 1.32 & 1.04 & - & 1.69 & 0.02 \\
\hline Dislipidemia & 1.05 & 0.82 & - & 1.35 & 0.67 & 1.11 & 0.87 & - & 1.43 & 0.39 \\
\hline Diabetes & 0.73 & 0.48 & - & 1.09 & 0.13 & 0.73 & 0.48 & - & 1.11 & 0.14 \\
\hline Cerebrovascular disease & 1.72 & 0.77 & - & 3.85 & 0.18 & 1.82 & 0.81 & - & 4.09 & 0.15 \\
\hline Chronic heart disease & 1.61 & 1.05 & - & 2.48 & 0.03 & 1.57 & 1.01 & - & 2.43 & 0.04 \\
\hline Height loss & - & - & & - & - & 1.14 & 1.08 & & 1.20 & $<0.01$ \\
\hline
\end{tabular}


Table 3 Odds ratios for low back pain in men $(n=898)$ by multivariate logistic regression models

\begin{tabular}{|c|c|c|c|c|c|c|c|c|c|c|}
\hline & \multicolumn{5}{|c|}{ Model 1} & \multicolumn{5}{|c|}{ Model 2} \\
\hline & \multirow{2}{*}{$\begin{array}{l}\mathrm{OR} \\
1.00\end{array}$} & \multicolumn{3}{|c|}{$95 \% \mathrm{Cl}$} & \multirow{2}{*}{$\begin{array}{l}p \text {-value } \\
0.83\end{array}$} & \multirow{2}{*}{$\begin{array}{l}\text { OR } \\
0.99\end{array}$} & \multicolumn{3}{|c|}{$95 \% \mathrm{Cl}$} & \multirow{2}{*}{$\begin{array}{l}p \text {-value } \\
0.25\end{array}$} \\
\hline & & 0.97 & - & 1.02 & & & 0.96 & - & 1.01 & \\
\hline Body height & 0.98 & 0.95 & - & 1.00 & 0.10 & 0.99 & 0.97 & - & 1.02 & 0.67 \\
\hline Muscle mass & 1.05 & 0.99 & - & 1.12 & 0.11 & 1.04 & 0.98 & - & 1.11 & 0.20 \\
\hline Fat mass & 1.00 & 0.96 & - & 1.03 & 0.76 & 1.00 & 0.96 & - & 1.03 & 0.82 \\
\hline Smoking & 1.26 & 0.86 & - & 1.84 & 0.23 & 1.21 & 0.83 & - & 1.77 & 0.32 \\
\hline Alcohol & 0.97 & 0.72 & - & 1.31 & 0.83 & 0.95 & 0.70 & - & 1.29 & 0.75 \\
\hline History of fall & 1.74 & 1.16 & - & 2.61 & 0.01 & 1.70 & 1.13 & - & 2.56 & 0.01 \\
\hline Hypertension & 1.19 & 0.89 & - & 1.61 & 0.24 & 1.21 & 0.90 & - & 1.63 & 0.21 \\
\hline Dislipidemia & 1.00 & 0.70 & - & 1.44 & 1.00 & 1.07 & 0.74 & - & 1.54 & 0.72 \\
\hline Diabetes & 0.89 & 0.59 & - & 1.33 & 0.56 & 0.92 & 0.61 & - & 1.38 & 0.69 \\
\hline Cerebrovascular disease & 1.80 & 1.01 & - & 3.18 & 0.04 & 1.88 & 1.05 & - & 3.34 & 0.03 \\
\hline Chronic heart disease & 0.75 & 0.47 & - & 1.19 & 0.22 & 0.75 & 0.47 & - & 1.19 & 0.22 \\
\hline Height loss & - & - & & - & - & 1.13 & 1.06 & & 1.21 & $<0.01$ \\
\hline
\end{tabular}

In general, it is sometimes difficult to identify the specific pathology or causal disorder among subjects with LBP [53-55]. Nevertheless, the relationship between height loss and LBP was reported around two decades ago. Huang et al. reported a positive correlation between the number of vertebral fractures and the degree of back pain [56]. Ismail et al. reported an association between vertebral deformities and LBP and significant relationship between the number of deformed vertebrae and height loss [23]. It was thought that overloading the lumbar intervertebral discs may cause height loss and LBP [57]. Indeed, in a study of Japanese people, lumbar compression fractures and lumbar disc herniation were shown to be likely causes of LBP [58]. Another mechanism may be that shortened para spinal muscles may compress an intervertebral disk, leading to nerve root compression and pain [59]. Taken together, spinal degeneration or vertebral compression fracture, both highly related to height loss, appear to be major causes of LBP. In this regard, obesity has been thought to be linked to LBP [16-18, 20, 21, 25-27]. Livshits et al., in a study of twin women, reported that the risk factors of LBP were obesity and lumbar disc degeneration [60]. However, in the present study, body weight and BMI were not associated with LBP, suggesting that obesity might not be a major cause of LBP, at least in elderly Japanese people. For this reason, our subjects presumably showed much lower prevalence and/or milder degree of obesity, compared with those of other reports.

Regarding body composition, we did not find a significant association between LBP and muscle mass or of fat mass. These results were consistent with findings reported by Iizuka et al. [31]. Nevertheless, conflicting findings have been reported regarding an association between muscle mass and LBP. Some researchers showed a significant association of muscle mass reduction with LBP [24, 26, 27, 60], while others reported no association $[25,61,62]$. On the other hand, previous reports have shown positive associations between fat mass and LBP [24, 25]. Hussain et al. analyzed women with mean age of 50 years old, and showed a negative association of fat-free mass with LBP intensity [26]. Urquhart et al. reported a positive association between $\%$ fat and LBP in subjects with mean age of 47 years old [27, 61]. Because fat tissue secretes cytokines such as tumor necrosis factor and interleukin-6 [62], higher the body fat percentage and central adiposity correlates with higher levels of acute phase inflammatory proteins such as C-reactive protein $[63,64]$. Furthermore, adipose mass and central adiposity were regarded as risk factors for knee and hip joint replacement $[65,66]$.

There are several limitations in this study. First, it is impossible to infer a causal relationship between LBP and the related factors, because this was a cross-sectional study. For example, the presence of LBP may lead to height loss due to difficulties of an extension of back muscle. On the other hand, LBP probably results from height loss because of skeletal disorders such as compression fractures, disc herniations, kyphosis, and degenerative spine disorders. Therefore, further studies are needed to analyze the causal relationship between LBP and physical characteristics, body composition, and chronic diseases. Second, we did not consider the severity, duration, and site of LBP. These factors may affect the relationship of LBP with height loss. Third, because tallest height was self-reported, recall bias may exist. Nevertheless, there were no official records, and we performed this study following the methods used in previous studies [24,35]. Due 
to existence of such limitations, further studies are needed to clarify these issues.

\section{Conclusions}

In the present cross-sectional study, we found that body composition was not significantly associated with LBP in both men and women, whereas height loss was a strong related factor of LBP in community-dwelling elderly individuals.

It was suggested that postural changes in elderly people due to height loss and the causative disease may lead to LBP whereas postural changes due to LBP may also cause height loss.

\section{Additional file}

Additional file 1: Table S1. Correlation coefficients between different measures of body mass. *; $p<0.05,{ }^{* *} ; p<0.01$. (XLSX $25 \mathrm{~kb}$ )

Additional file 2: Table S2. A multiple linear regression analysis on height loss with the present body height and body weight. (XLSX $27 \mathrm{~kb}$ )

\section{Abbreviations}

BIA: Bioelectrical impedance analysis; BMI: Body mass index; Cl: Confidence interval; LBP: Low back pain; OR: Odds ratio; QUS: Quantitative ultrasound; SD: Standard deviation; YAM: Young adult mean

\section{Acknowledgments}

Authors appreciate all the CoHRE study members for their skillful assistance.

\section{Author contributions}

Conceived and designed the experiments: TE, TA, KA, and SY; collected the data: TA, TK, MT, MY, MI, TN, and SY; analyzed the data: TE, TA, and KA; contributed reagents/materials/analysis tools: TA, KA, TN, and SY; wrote the manuscript: TE, TA, and SY. All authors read and approved the final manuscript.

\section{Funding}

The authors received no specific funding for this work. The funders had no role in study design, data collection and analysis, decision to publish, or preparation of the manuscript.

\section{Availability of data and materials}

The datasets used and/or analyzed during the current study are available from the corresponding author on reasonable request.

\section{Ethics approval and consent to participate}

This study was approved by the local ethics committee of Shimane University (\#3149) and Unnan City Hospital (\#20180004) and in accordance to the Declaration of Helsinki. Written informed consent was obtained from all participants.

\section{Consent for publication}

Not applicable.

\section{Competing interests}

The authors declare that they have no competing interests.

\section{Publisher's Note}

Springer Nature remains neutral with regard to jurisdictional claims in published maps and institutional affiliations.

\section{Author details}

'Division of Internal Medicine, Unnan City Hospital, Unnan-city, Shimane, Japan. ${ }^{2}$ Center for Community-Based Healthcare Research and Education (CoHRE), Shimane University, Matsue-city, Shimane, Japan. ${ }^{3}$ Department of
General Medicine, Shimane University Faculty of Medicine, Izumo-city, Shimane, Japan. ${ }^{4}$ Shimane University Faculty of Human Sciences, Matsue-city, Shimane, Japan. ${ }^{5}$ Department of Functional Pathology, Shimane University Faculty of Medicine, Izumo-city, Shimane, Japan. ${ }^{6}$ Department of Laboratory Medicine, Shimane University Faculty of Medicine, Izumo-city, Shimane, Japan.

Received: 4 November 2018 Accepted: 22 April 2019

Published online: 10 May 2019

\section{References}

1. Hiyama A, Watanabe M, Katoh H, Sato M, Sakai D, Mochida J. Evaluation of quality of life and neuropathic pain in patients with low Back pain using the Japanese orthopedic association Back pain evaluation questionnaire. Eur Spine J. 2015;24:503-12.

2. Hirano K, Imagama S, Hasegawa $Y$, Ito Z, Muramoto A, Ishiguro N. Impact of low back pain, knee pain, and timed up-and-go test on quality of life in community-living people. J Orthop Sci. 2014;19:164-71.

3. Reid MC, Williams CS, Gill TM. Back pain and decline in lower extremity physical function among community-dwelling older persons. J Gerontol A Biol Sci Med Sci. 2005:60:793-7.

4. Hicks GE, Simonsick EM, Harris TB, Newman AB, Weiner DK, Nevitt MA, Tylavsky FA. Trunk muscle composition as a predictor of reduced functional capacity in the health, aging and body composition study: the moderating role of back pain. J Gerontol A Biol Sci Med Sci. 2005;60:1420-4.

5. Hicks GE, Sions JM, Coyle PC, Pohlig RT. Altered spatiotemporal characteristics of gait in older adults with chronic low back pain. Gait Posture. 2017:55:172-6.

6. Walker B, Muller R, Grant W. Low back pain in Australian adults: the economic burden. Asia Pac J Public Health. 2003:15:79-87.

7. Dagenais S, Caro J, Haldeman S. A systematic review of low back pain cost of illness studies in the United States and internationally. Spine J. 2008;8:8-20.

8. Gore M, Sadosky A, Stacey BR, Tai K-S, Leslie D. The burden of chronic low back pain: clinical comorbidities, treatment patterns, and health care costs in usual care settings. Spine (Phila Pa 1976). 2012;37:E668-77.

9. Sadosky AB, DiBonaventura M, Cappelleri JC, Ebata N, Fujii K. The association between lower back pain and health status, work productivity, and health care resource use in Japan. J Pain Res. 2015:8:119.

10. Walker BF. The prevalence of low back pain: a systematic review of the literature from 1966 to 1998. Clin Spine Surg. 2000;13:205-17.

11. Yoshimura N, Akune T, Fujiwara S, Shimizu Y, Yoshida H, Omori G, et al. Prevalence of knee pain, lumbar pain and its coexistence in Japanese men and women: the longitudinal cohorts of motor system organ (LOCOMO) study. J Bone Miner Metab. 2014;32:524-32.

12. Aro S, Leino P. Overweight and musculoskeletal morbidity: a ten-year follow-up. Int J Obes. 1985;9:267-75.

13. Han T, Schouten J, Lean M, Seidell J. The prevalence of low back pain and associations with body fatness, fat distribution and height. Int J Obes. 1997:21:600.

14. Croft PR, Papageorgiou AC, Thomas E, Macfarlane GJ, Silman AJ. Short-term physical risk factors for new episodes of low back pain: prospective evidence from the South Manchester Back pain study. Spine (Phila Pa 1976). 1999:24:1556.

15. Leboeuf-Yde C. Body weight and low back pain: a systematic literature review of 56 journal articles reporting on 65 epidemiologic studies. Spine (Phila Pa 1976). 2000;25:226.

16. Shiri R, Karppinen J, Leino-Arjas P, Solovieva S, Viikari-Juntura E. The association between obesity and low back pain: a meta-analysis. Am J Epidemiol. 2009;171:135-54.

17. Nilsen TIL, Holtermann A, Mork PJ. Physical exercise, body mass index, and risk of chronic pain in the low back and neck/shoulders: longitudinal data from the Nord-Trøndelag health study. Am J Epidemiol. 2011;174:267-73.

18. Heuch I, Heuch I, Hagen K, Zwart J-A. Body mass index as a risk factor for developing chronic low back pain: a follow-up in the Nord-Trøndelag health study. Spine (Phila Pa 1976). 2013;38:133-9.

19. Walsh K, Cruddas M, Coggon D. Interaction of height and mechanical loading of the spine in the development of low-back pain. Scand J Work Environ Health. 1991;17:420-4.

20. Hershkovich O, Friedlander A, Gordon B, Arzi H, Derazne E, Tzur D, et al. Associations of body mass index and body height with low back pain in 829,791 adolescents. Am J Epidemiol. 2013;178:603-9. 
21. Heuch I, Heuch I, Hagen K, Zwart J-A. Association between body height and chronic low back pain: a follow-up in the Nord-Trøndelag health study. BMJ Open. 2015;5:e006983.

22. Inoue G, Miyagi M, Uchida K, Ishikawa T, Kamoda H, Equchi Y, et al. The prevalence and characteristics of low back pain among sitting workers in a Japanese manufacturing company. J Orthop Sci. 2015;20:23-30.

23. Ismail AA, Cooper C, Felsenberg D, Varlow J, Kanis JA, Silman AJ, et al. Number and type of vertebral deformities: epidemiological characteristics and relation to back pain and height loss. European Vertebral Osteoporosis Study Group. Osteoporos Int. 1999;9:206-13.

24. Kamimura M, Nakamura Y, Sugino N, Uchiyama S, Komatsu M, Ikegami S, et al. Associations of self-reported height loss and kyphosis with vertebral fractures in Japanese women 60 years and older: a cross-sectional survey. Sci Rep. 2016;6:29199.

25. Dario AB, Ferreira ML, Refshauge K, Sánchez-Romera JF, Luque-Suarez A, Hopper $J$, et al. Are obesity and body fat distribution associated with low back pain in women? A population-based study of 1128 Spanish twins. Eur Spine J. 2016;25:1188-95.

26. Hussain SM, Urquhart DM, Wang Y, Shaw JE, Magliano DJ, Wluka AE, et al. Fat mass and fat distribution are associated with low back pain intensity and disability: results from a cohort study. Arthritis Res Ther. 2017;19:26.

27. Urquhart DM, Berry P, Wluka AE, Strauss BJ, Wang Y, Proietto J, et al. Young investigator award winner: increased fat mass is associated with high levels of low back pain intensity and disability. Spine (Phila pa 1976). 2011. 2011; 36:1320-5.

28. Wallwork TL, Stanton WR, Freke M, Hides JA. The effect of chronic low back pain on size and contraction of the lumbar multifidus muscle. Man Ther. 2009;14:496-500.

29. Danneels LA, Vanderstraeten GG, Cambier DC, Witvrouw EE, De Cuyper HJ. $C T$ imaging of trunk muscles in chronic low back pain patients and healthy control subjects. Eur Spine J. 2000;9:266-72.

30. Goubert D, Van Oosterwijck J, Meeus M, Danneels L. Structural changes of lumbar muscles in non-specific low back pain: a systematic review. Pain physician. 2016;19:E985-E1000.

31. lizuka Y, lizuka H, Mieda T, Tajika T, Yamamoto A, Ohsawa T, et al. Association between neck and shoulder pain, back pain, low back pain and body composition parameters among the Japanese general population. BMC Musculoskelet Disord. 2015;16:333.

32. Verney J, Metz L, Chaplais E, Cardenoux C, Pereira B, Thivel D. Bioelectrical impedance is an accurate method to assess body composition in obese but not severely obese adolescents. Nutr Res. 2016;36:663-70.

33. Pietrobelli A, Rubiano F, St-Onge M, Heymsfield S. New bioimpedance analysis system: improved phenotyping with whole-body analysis. Eur J Clin Nutr. 2004;58:1479

34. Takeda M, Hamano T, Kohno K, Yano S, Shiwaku K, Nabika T. Association between geographic elevation, bone status, and exercise habits: the Shimane CoHRE study. Int J Environ Res Public Health. 2015;12:7392-9.

35. Briot K, Legrand E, Pouchain D, Monnier S, Roux C. Accuracy of patientreported height loss and risk factors for height loss among postmenopausal women. CMAJ. 2010;182:558-62.

36. Kerkhoff AC, Moreira LB, Fuchs FD, Fuchs SC. Association between hypertension and musculoskeletal complaints: a population-based study. J Hypertens. 2012;30:2112-7.

37. Pechlivanova DM, Markova PP, Stoynev AG. Effect of the AT(1) receptor antagonist losartan on diurnal variation in pain threshold in spontaneously hypertensive rats. Methods Find Exp Clin Pharmacol. 2010;32:663-8.

38. Bae $\mathrm{YH}$, Shin JS, Lee J, Kim MR, Park KB, Cho JH, et al. Association between hypertension and the prevalence of low back pain and osteoarthritis in Koreans: a cross-sectional study. PLoS One. 2015;10:e0138790.

39. Fayaz A, Ayis S, Panesar SS, Langford RM, Donaldson LJ. Assessing the relationship between chronic pain and cardiovascular disease: a systematic review and meta-analysis. Scand J Pain. 2016;13:76-90.

40. Shmagel A, Foley R, Ibrahim H. Epidemiology of chronic low back pain in US adults: data from the 2009-2010 National Health and nutrition examination survey. Arthritis Care Res (Hoboken). 2016;68:1688-94.

41. Maher C, Underwood M, Buchbinder R. Non-specific low back pain. Lancet. 2017:389:736-47

42. Hagen K, Zwart JA, Holmen J, Svebak S, Bovim G, Stovner LJ. Does hypertension protect against chronic musculoskeletal complaints? The Nord-Trondelag health study. Arch Intern Med. 2005;165:916-22.

43. Heliövaara M. Body height, obesity, and risk of herniated lumbar intervertebral disc. Spine (Phila pa 1976), vol. 12; 1987. p. 469-72.
44. Peter RS, Fromm E, Klenk J, Concin H, Nagel G. Change in height, weight, and body mass index: longitudinal data from Austria. Am J Hum Biol. 2014;26:690-6.

45. Jarraya M, Guermazi A, Lorbergs AL, Brochin E, Kiel DP, Bouxsein ML, et al. A longitudinal study of disc height narrowing and facet joint osteoarthritis at the thoracic and lumbar spine, evaluated by computed tomography: the Framingham study. Spine J. 2018;18:2065-73.

46. Videman $T$, Levälahti $E$, Battié MC. The effects of anthropometrics, lifting strength, and physical activities in disc degeneration. Spine (Phila Pa 1976). 2007;32:1406-13.

47. Galbusera F, Van Rijsbergen M, Ito K, Huyghe JM, Brayda-Bruno M, Wilke H-J. Ageing and degenerative changes of the intervertebral disc and their impact on spinal flexibility. Eur Spine J. 2014;23:324-32.

48. Cosman F, De Beur S, LeBoff M, Lewiecki E, Tanner B, Randall S, et al. Clinician's guide to prevention and treatment of osteoporosis. Osteoporos Int. 2014:25:2359-81.

49. Mikula A, Hetzel S, Binkley N, Anderson P. Validity of height loss as a predictor for prevalent vertebral fractures, low bone mineral density, and vitamin D deficiency. Osteoporos Int. 2017;28:1659-65.

50. Ettinger B, Black DM, Nevitt MC, Rundle AC, Cauley JA, Cummings SR, et al. Contribution of vertebral deformities to chronic back pain and disability. The study of osteoporotic fractures research group. J Bone Miner Res. 1992; 7:449-56.

51. Vergroesen P-PA, van der Veen AJ, van Royen BJ, Kingma I, Smit TH. Intradiscal pressure depends on recent loading and correlates with disc height and compressive stiffness. Eur Spine J. 2014;23:2359-68.

52. Urquhart DM, Kurniadi I, Triangto K, Wang Y, Wluka AE, O'Sullivan R, et al. Obesity is associated with reduced disc height in the lumbar spine but not at the lumbosacral junction. Spine (Phila Pa 1976). 2014;39:E962-6.

53. Deyo RA. Diagnostic evaluation of LBP: reaching a specific diagnosis is often impossible. Arch Intern Med. 2002;162:1444-7.

54. Henschke N, Maher CG, Refshauge KM, Herbert RD, Cumming RG, Bleasel J, et al. Prevalence of and screening for serious spinal pathology in patients presenting to primary care settings with acute low back pain. Arthritis Rheum. 2009;60:3072-80

55. Enthoven WT, Geuze J, Scheele J, Bierma-Zeinstra SM, Bueving HJ, Bohnen AM, et al. Prevalence and "red flags" regarding specified causes of back pain in older adults presenting in general practice. Phys Ther. 2016;96:305-12.

56. Huang C, Ross PD, Wasnich RD. Vertebral fractures and other predictors of back pain among older women. J Bone Miner Res. 1996;1 1:1026-32

57. McNally DS, Shackleford IM, Goodship AE, Mulholland RC. In vivo stress measurement can predict pain on discography. Spine (Phila Pa 1976). 1996; 21:2580-7.

58. Suzuki H, Kanchiku T, Imajo Y, Yoshida Y, Nishida N, Taguchi T. Diagnosis and characters of non-specific low back pain in Japan: the Yamaguchi low back pain study. PLoS One. 2016;11:e0160454.

59. Gunn CC. Neuropathic myofascial pain syndromes. In: Bonica's Management of Pain. Philadelphia: Lippincott Williams \& Wilkins; 2001. p. 522-9.

60. Livshits G, Popham M, Malkin I, Sambrook PN, MacGregor AJ, Spector T, et al. Lumbar disc degeneration and genetic factors are the main risk factors for low back pain in women: the UK twin spine study. Ann Rheum Dis. 2011;70:1740-5.

61. Hebert JJ, Kjaer P, Fritz JM, Walker BF. The relationship of lumbar multifidus muscle morphology to previous, current, and future low back pain: a 9-year populationbased prospective cohort study. Spine (Phila Pa 1976). 2014;39:1417-25.

62. Pottie $P$, Presle $N$, Terlain B, Netter $P$, Mainard D, Berenbaum F. Obesity and osteoarthritis: more complex than predicted! Ann Rheum Dis. 2006;65:1403-5.

63. Thorand B, Baumert J, Doring A, Herder C, Kolb H, Rathmann W, et al. Sex differences in the relation of body composition to markers of inflammation. Atherosclerosis. 2006:184:216-24.

64. Park HS, Park JY, Yu R. Relationship of obesity and visceral adiposity with serum concentrations of CRP, TNF- $a$ and IL-6. Diabetes Res Clin Pract. 2005; 69:29-35.

65. Wang Y, Simpson JA, Wluka AE, Teichtahl AJ, English DR, Giles GG, et al. Relationship between body adiposity measures and risk of primary knee and hip replacement for osteoarthritis: a prospective cohort study. Arthritis Res Ther. 2009:11:R31.

66. Lohmander LS, de Verdier MG, Rollof J, Nilsson PM, Engström G. Incidence of severe knee and hip osteoarthritis in relation to different measures of body mass: a population-based prospective cohort study. Ann Rheum Dis. 2009;68:490-6. 